\title{
What Is the Role of Informal Healthcare Providers in Developing Countries? A Systematic Review
}

\author{
May Sudhinaraset ${ }^{1 *}$, Matthew Ingram², Heather Kinlaw Lofthouse ${ }^{3}$, Dominic Montagu'
}

1 Global Health Sciences, University of California San Francisco, San Francisco, California, United States of America, 2 Metta Fund, Corte Madera, California, United States of America, 3 Absolute Return for Kids US, New York, New York, United States of America

\begin{abstract}
Informal health care providers (IPs) comprise a significant component of health systems in developing nations. Yet little is known about the most basic characteristics of performance, cost, quality, utilization, and size of this sector. To address this gap we conducted a comprehensive literature review on the informal health care sector in developing countries. We searched for studies published since 2000 through electronic databases PubMed, Google Scholar, and relevant grey literature from The New York Academy of Medicine, The World Bank, The Center for Global Development, USAID, SHOPS (formerly PSP-One), The World Health Organization, DFID, Human Resources for Health Global Resource Center. In total, 334 articles were retrieved, and 122 met inclusion criteria and chosen for data abstraction. Results indicate that IPs make up a significant portion of the healthcare sector globally, with almost half of studies (48\%) from Sub-Saharan Africa. Utilization estimates from 24 studies in the literature of IP for healthcare services ranged from $9 \%$ to $90 \%$ of all healthcare interactions, depending on the country, the disease in question, and methods of measurement. IPs operate in a variety of health areas, although baseline information on quality is notably incomplete and poor quality of care is generally assumed. There was a wide variation in how quality of care is measured. The review found that IPs reported inadequate drug provision, poor adherence to clinical national guidelines, and that there were gaps in knowledge and provider practice; however, studies also found that the formal sector also reported poor provider practices. Reasons for using IPs included convenience, affordability, and social and cultural effects. Recommendations from the literature amount to a call for more engagement with the IP sector. IPs are a large component of nearly all developing country health systems. Research and policies of engagement are needed.
\end{abstract}

Citation: Sudhinaraset M, Ingram M, Lofthouse HK, Montagu D (2013) What Is the Role of Informal Healthcare Providers in Developing Countries? A Systematic Review. PLoS ONE 8(2): e54978. doi:10.1371/journal.pone.0054978

Editor: Gemma Elizabeth Derrick, Consejo Superior de Investigaciones Cientifics, Spain

Received June 28, 2012; Accepted December 22, 2012; Published February 6, 2013

Copyright: (C) 2013 Sudhinaraset et al. This is an open-access article distributed under the terms of the Creative Commons Attribution License, which permits unrestricted use, distribution, and reproduction in any medium, provided the original author and source are credited.

Funding: Results for Development provided funds to complete this systematic review. The funders had no role in study design, data collection and analysis, decision to publish, or preparation of the manuscript.

Competing Interests: The authors have declared that no competing interests exist.

* E-mail: sudhinarasetm@globalhealth.ucsf.edu

\section{Introduction}

In many developing nations, the informal sector provides the bulk of health care, particularly for the poor [1]. Literature on the subject of informal providers (IPs) resides in silos related to narrow fields and, to date, few researchers have evaluated the nature and impact of the informal provision of health care. In addition, while there is little evidence on the quality of care provided by IPs, there is general acceptance that IPs provide substandard care [2]. We assess the literature on the scope and practice, size and utilization patterns, quality, and reasons people use IPs. In addition, we summarize recommendations in regards to IPs in the developing world.

\section{Defining Informal Provider}

While the precise definition of the term "informal health care providers" is inconsistent across studies [2] and we found no developed typology in the literature, we provide a working definition in order to identify relevant studies. We used a flexible set of criteria as opposed to specific delineations for characteristics such as duration of training or group membership. Such rigid definitions are inappropriately constrictive in light of significant contextual variation. To be classified as such, IPs must meet our first criteria below, and at least two of the remaining three criterion.

The set of definitional criteria include:

1. Training: IPs include those who have not received formally recognized training with a defined curriculum from an institution (i.e. government, NGO, or academic institution). IPs, however, typically have some level of informal training through apprenticeships, seminars, and workshops, and are typically not mandated by any formal institution.

2. Payment: IPs collect payment from patients served, not from institutions. One notable exception to this criterion involves NGO or other sponsored voucher programs, where informal providers exchange services or goods for payment from a sponsoring body in the form of reimbursement vouchers. Payment is usually, but not always, un-documented and tendered in cash. IPs are chiefly entrepreneurs.

3. Registration and regulation: IPs are not typically registered with any government regulatory body and operate outside of the purview of regulation, registration, or oversight by the government or other institutions 
4. Professional affiliation: IP professional associations, if they exist, are primarily focused on networking and business activities and conduct minimal self-regulation.

IPs are a heterogeneous group of providers with differences in type of training, regulatory frameworks, and services provided; however, in this paper, we purposefully decided to take an inclusive approach and include in the results and discussions all types of informal providers in to one category for a number of reasons. First, local governments tend to think of providers outside the formal sector as one group with little knowledge on the size and utilization of this sector. A comprehensive global summary is needed given the lack of information known. Second, the current literature typically does not specify what type of informal provider is included or else includes multiple types of informal providers in the study. It is quite common that informal providers in different contexts are performing similar preventative and curative activities, even if they have different titles depending on their locale. Therefore, key lessons learned can translate to a variety of providers who are untrained and work outside regulatory frameworks. Because caregivers do not receive payment for services, and therefore fail to meet the first of our key definitional criteria, we excluded them even though they feature many of the same traits and practice in a similar fashion to other IPs. Community health workers who were trained by NGOs or governments are not included in the study. Only studies that specify "untrained" community health workers are included the study results.

\section{Methods}

Using an expanded keyword search list, we searched electronic databases and websites for relevant published and grey literature. A larger study conducted in mid- 2010 on informal providers looked at multiple databases and languages and found widespread duplication of materials and language-based confusion of terms used to describe informal providers. On the basis of that experience we limited this search to only English language studies, and only two electronic datasets; supplemented with multilanguage grey literature searches. We queried the following electronic databases for relevant published literature: PubMed, Google Scholar; and searched the following websites for relevant grey literature: The New York Academy of Medicine, The World Bank, The Center for Global Development, USAID, SHOPS (formerly PSP-One), The World Health Organization, DFID, Human Resources for Health Global Resource Center.

To identify studies conducted on IPs, a set of search terms was used (see Table 1). Inclusion criteria for the review were: studies conducted in a low or middle-income country (LMIC), conducted in 2000 or after, and reported data on a health outcome. We restricted inclusion only to articles where informal providers were the focus of the article, meaning that the search terms appeared in the title or abstract. The search identified approximately 3,000 articles, which were then screened to determine if the study occurred in a low- or middle-income country as defined by the World Bank. In total, 334 articles were included for review, of which 103 were over a decade old (pre-year 2000), and were therefore excluded from further analysis. Of the 231 remaining articles, 122 were chosen for data abstraction after reviewers ensured the studies met the inclusion criteria. The protocol for identifying studies can be found at: http://cl.ly/ 3y232d0k1E2R2c301R0k. This includes criteria for considering types of studies for review, electronic searches, and data extraction and management. Only studies based on primary data were included.
Table 1. Search Terms for Informal Providers.

\begin{tabular}{|c|c|}
\hline Alternative healer & Less than fully qualified practitioner \\
\hline Alternative health practitioner & Local medical practitioner \\
\hline Alternative health provider & Medical detailer \\
\hline Alternative medical practitioner & Non-graduate medical practitioner \\
\hline Alternative medical provider & Non-registered health care provider \\
\hline Alternative practitioner & Non-state actor \\
\hline Alternative provider & Patent medicine vendor \\
\hline Ayurved & Pharmacy worker \\
\hline Ayurveda & Private sector \\
\hline Community health worker & Quack \\
\hline Compounder & Rural medical practitioner \\
\hline Detailer & Rural practitioner \\
\hline Drug seller & Semi-qualified provider \\
\hline Drug vendor & Shopkeeper \\
\hline Folk medicine & Traditional birth attendant \\
\hline Folk practitioner & Traditional healer \\
\hline Hakeem & Traditional medical practitioner \\
\hline Healer & Traditional practitioner \\
\hline Herbalist & Traditional provider \\
\hline Homeopath & Traditional therapists \\
\hline Indigenous practitioner & Unqualified allopathic provider \\
\hline Individual practitioner & Unqualified provider \\
\hline Informal provider & Untrained practitioner \\
\hline Informal sector & Untrained provider \\
\hline Lady health worker & Village doctor \\
\hline
\end{tabular}

Two researchers abstracted the data for the review. Each read and categorized all references and collected the following information for each: first author, year, title, region, country, type of IPs included, quality data, cost data, utilization data, size data, recommendations (two maximum per reference), type of study, type of intervention (if appropriate), intervention successful (if appropriate), disease discussed, and any important notes (i.e. target populations, \% received care from IP vs. other provider; \% received care from type of IP etc.). Data were entered into and analyzed using a Microsoft Excel database.

Due to a limited body of research on informal providers, the review includes all existing relevant research and types of study designs. There are inherent biases to including a range of study designs, including limitations in cross-sectional studies and the inability to establish causality when assessing interventions. In addition, publication bias may result in intervention studies due to the greater likelihood of publishing interventions with statistically significant results on specified outcomes. Size and utilization data are presented in Table 2. Study designs, sample size, and predictors of quality are reported in Table 3 for studies assessing the quality of IPs.

To assess the quality of IPs, we included studies that reported on technical or perceived dimensions of quality. Technical quality included adequacy of health provision determined by existing guidelines (i.e. national guidelines), counseling, referral rates, and health practice. Studies that reported on perceived quality, as reported by clients, were also included in the literature review. We excluded studies that only reported on provider-specific charac- 
Table 2. Size and Utilization of the Informal Healthcare Sector.

\begin{tabular}{|c|c|c|c|c|}
\hline Country & Study & IP Type & $\begin{array}{l}\text { Utilization (\% of } \\
\text { healthcare provided by } \\
\text { IP) }\end{array}$ & $\begin{array}{l}\text { Size (\% of providers that } \\
\text { are informal) }\end{array}$ \\
\hline \multicolumn{5}{|c|}{ Bangladesh } \\
\hline & (Ahmed 2005) & Multiple & 0.65 & - \\
\hline & (Ahmed, Hossain et al. 2009) & Multiple & - & 0.88 \\
\hline & (Bhuiya and Book 2009) & Multiple & - & 0.96 \\
\hline & (Hosain, Ganguly et al. 2005) & Multiple & 0.77 & - \\
\hline & (Cockcroft, Milne et al. 2004) & Multiple & 0.6 & - \\
\hline & (Levin, Rahman et al. 2001) & Multiple & 0.65 & - \\
\hline \multicolumn{5}{|l|}{ India } \\
\hline & (De Costa and Diwan 2007) & Untrained Provider, TBA & - & 0.55 \\
\hline & (Kanjilal, Mondal et al. 2007) & RMPs & $54 \% / 19 \%$ & - \\
\hline & (Rao 2005) & RMPs, Unknown & - & 0.51 \\
\hline \multicolumn{5}{|l|}{ Kenya } \\
\hline & (Amin, Marsh et al. 2003) & Multiple & 0.33 & - \\
\hline & (Hamel, Odhacha et al. 2001) & $\begin{array}{l}\text { CHW, Traditional Practitioner, } \\
\text { Drug Sellers }\end{array}$ & $9 \% / 32 \%$ & - \\
\hline \multicolumn{5}{|l|}{ Laos } \\
\hline & (Sydara, Gneunphonsavath et al. 2005) & & & \\
\hline \multicolumn{5}{|c|}{ Mozambique } \\
\hline & (Gloyd, Floriano et al. 2001) & TBA & 0.43 & - \\
\hline \multicolumn{5}{|l|}{ Multiple } \\
\hline & (Brieger, Osamor et al. 2004) & Drug Sellers & $15-82 \%$, Median = 50\% & - \\
\hline & (WHO and Organization) 2002) & Traditional Medicine & $60-90 \%$ & - \\
\hline & (Greer, Akinpelumi et al. 2004) & Multiple & $15-73 \%$ & - \\
\hline & (Tawfik, Northrup et al. 2002) & Multiple & $14-60 \%$ & - \\
\hline \multicolumn{5}{|l|}{ Nepal } \\
\hline & (Shankar, Partha et al. 2002) & Compounder & 0.36 & - \\
\hline \multicolumn{5}{|l|}{ Nigeria } \\
\hline & (Brieger, Salako et al. 2001) & Drug Sellers & 0.36 & - \\
\hline & (Enato and Okhamafe 2006) & Drug Sellers & 0.44 & - \\
\hline & (Salako, Brieger et al. 2001) & Drug Sellers & 0.49 & - \\
\hline & (Oladepo, Salami et al. 2008) & Drug Sellers & 0.39 & - \\
\hline \multicolumn{5}{|l|}{ Tanzania } \\
\hline & (Battersby, Goodman et al. 2003) & & & \\
\hline & (Corno 2008) & Multiple & 0.13 & - \\
\hline \multicolumn{5}{|l|}{ Thailand } \\
\hline & (Bryant and Prohmmo 2001) & Drug Sellers & $55-77 \%$ & - \\
\hline \multicolumn{5}{|l|}{ Uganda } \\
\hline & (Jacobs, Whitworth et al. 2004) & Drug Sellers & 0.35 & - \\
\hline & (Konde-Lule, Nakacubo Gitta et al. 2010) & Multiple & 0.11 & 0.77 \\
\hline & (Twebaze 2001) & Drug Sellers/Traditional Healers & $40 / 62 \%$ & - \\
\hline
\end{tabular}

doi:10.1371/journal.pone.0054978.t002

teristics, such as only knowledge, but reported knowledge level when combined with other quality predictors. Descriptive summary statistics such as percentage of utilization of IP sector across countries was used to assess size of informal providers sector. Descriptive statistics such as treatment rates, success rates, referral rates, and difference in means was used to assess quality of informal providers (see Table 3).

\section{Results}

A total of 334 references were gathered from the past eleven years (2000-2011). Upon reviewing abstracts, 103 were found to be pre-2000 and were therefore excluded from further analysis. In order to ensure the literature review reflects the current state of informal providers, a 2000-publishing cut-off was chosen; however, studies that used data pre-2000 were used for contextual and 


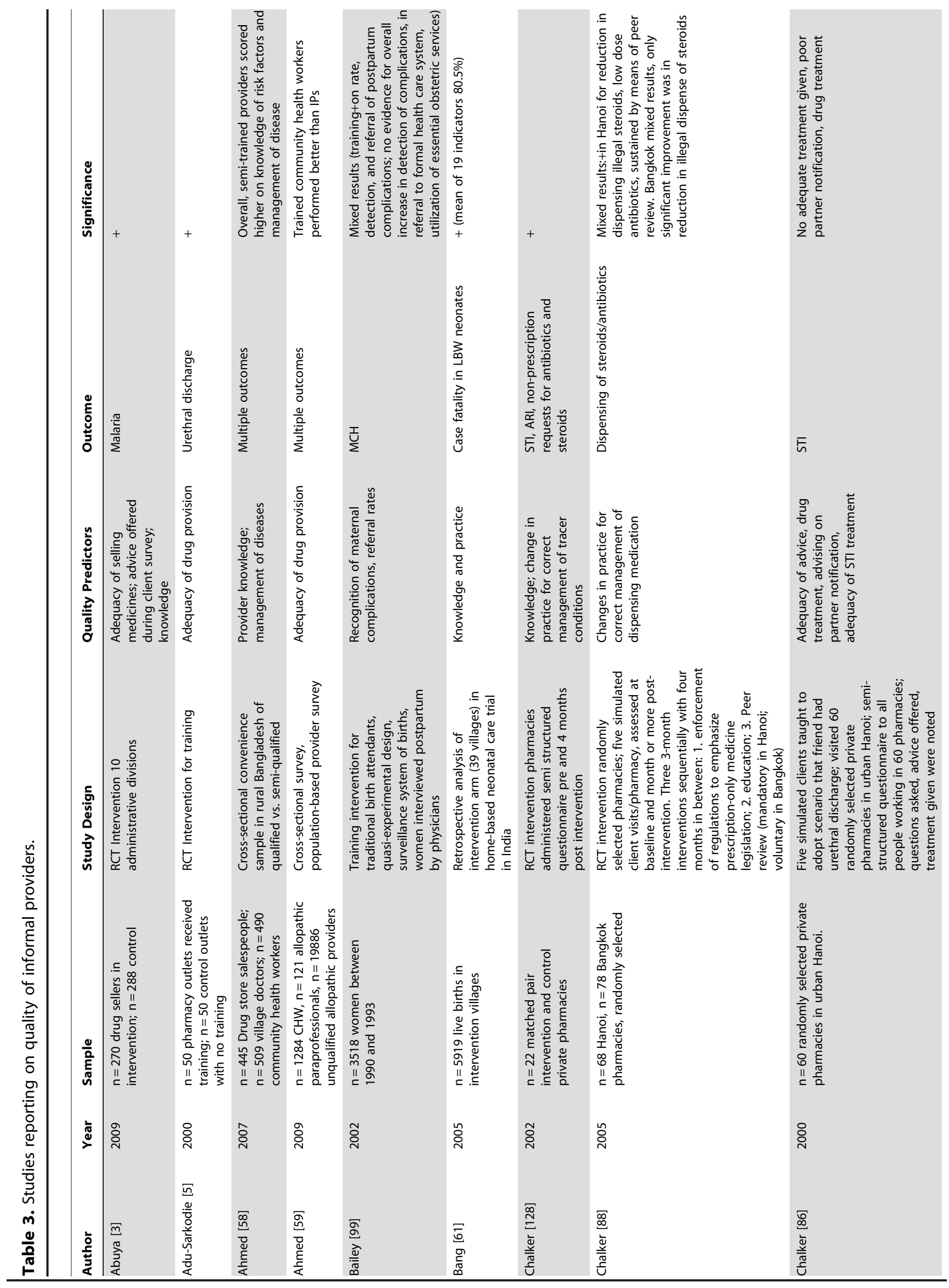




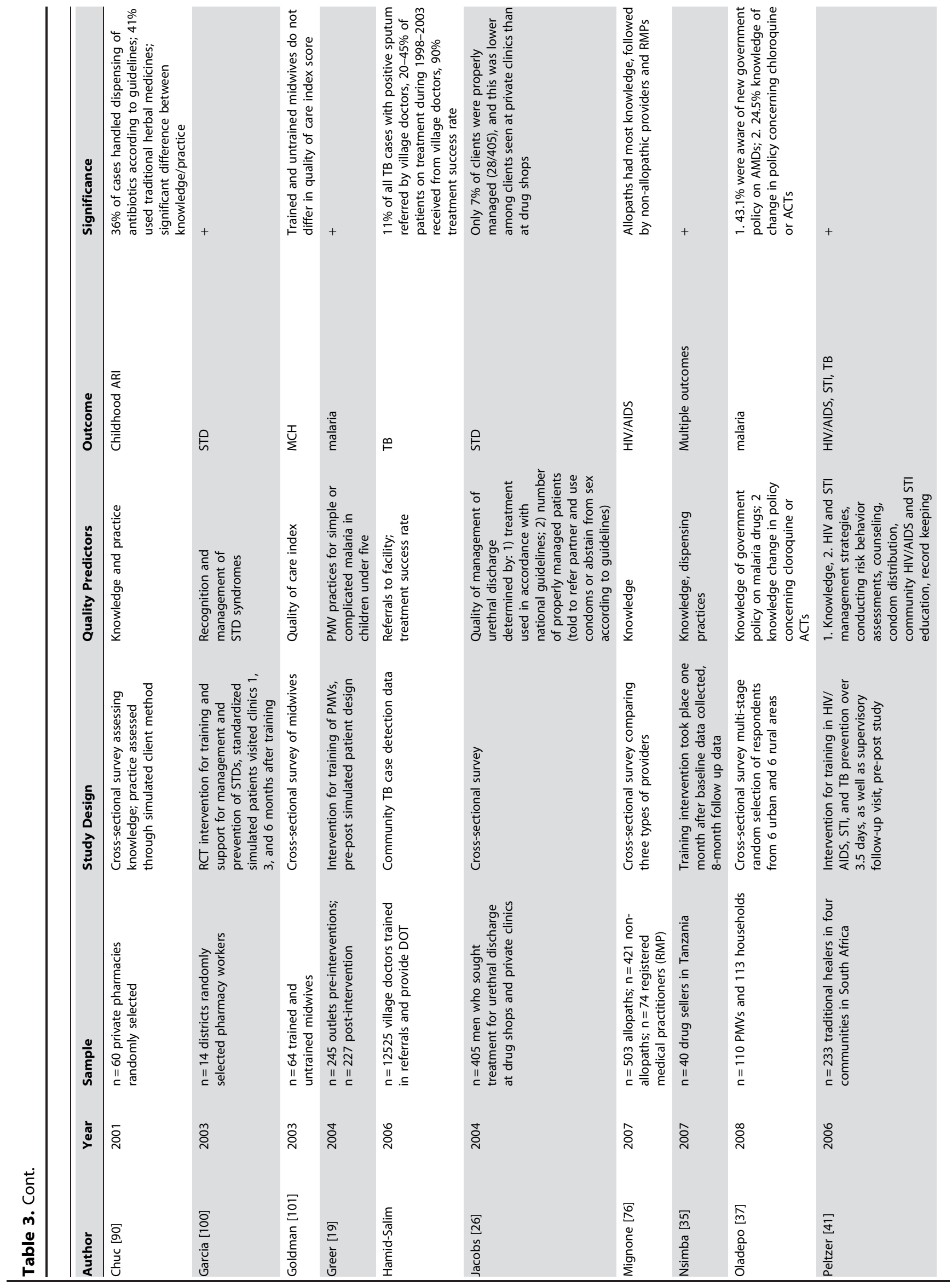




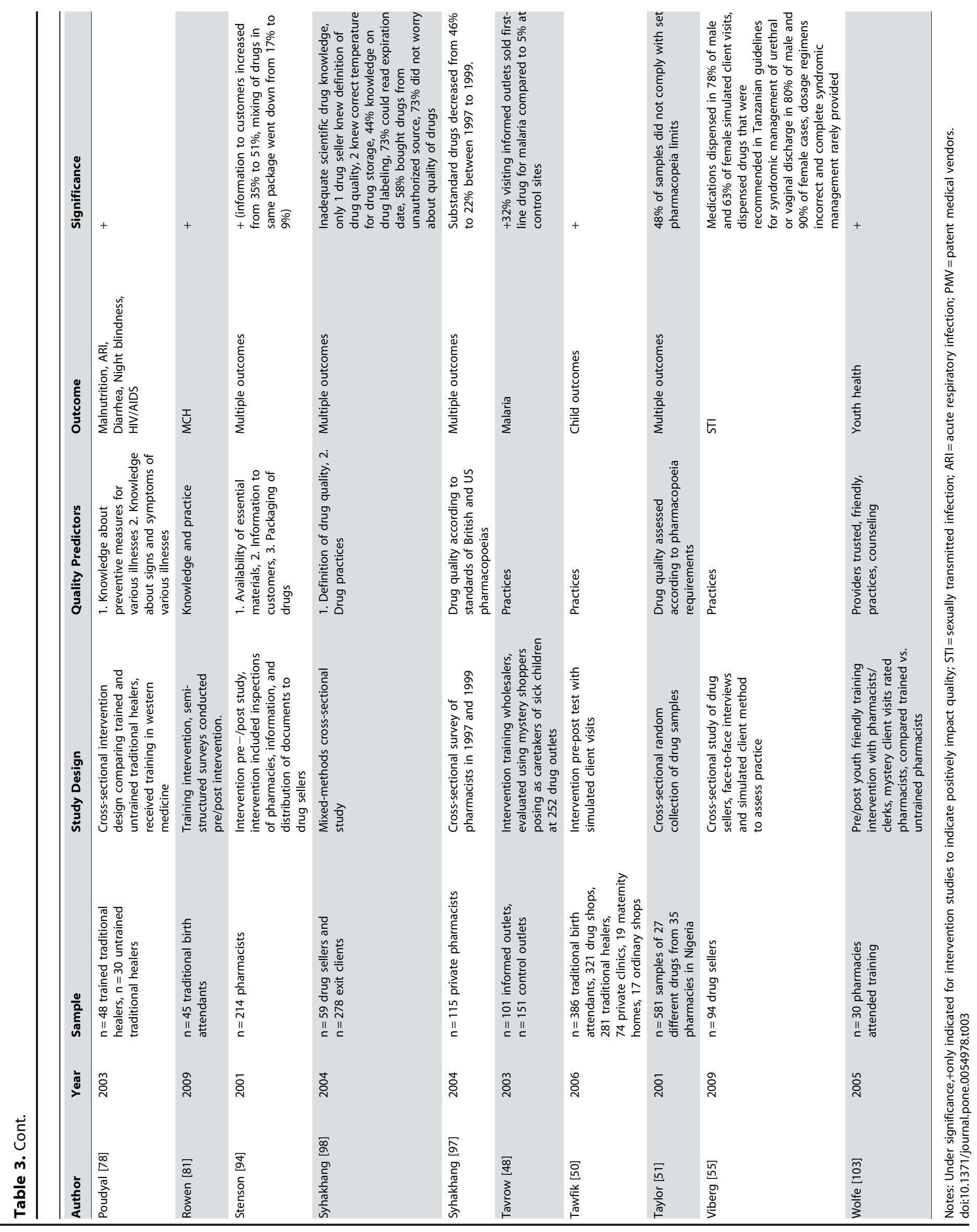


background information. Two hundred and thirty-one studies were included in the review: 122 were chosen for data abstraction. The remaining 109 references were indirectly relevant to the topic and provided additional context and background for the review. Regionally, almost half of the studies $(48.0 \%)$ of studies were from sub-Saharan Africa [3-56], followed by $23.5 \%$ in South Asia [5783], 12.6\% in Southeast Asia regions [84-98], and 4.2\% in Latin America [99-103]. Additionally, almost 12\% of articles covered multiple regions [104-115]. A total of 26, all low-or middleincome (LMIC) countries were represented in the references included for abstraction.

\section{The Scope of Practice of Informal Providers}

An IP's scope of practice is altered according to contextual variation. The robustness of the regulatory framework, strength of enforcement mechanisms, influence of cultural traditions, condition of the formal health infrastructure, and the demand for services all shape IPs' activities and may vary on a national or regional level. Informal providers operate in a variety of health areas. The literature search most commonly identified studies with "multiple disease areas" ( $\mathrm{n}=41 / 118)$. In disease-specific studies, maternal and child health was the most common area of study with 25 papers, followed by malaria $(n=22)$, HIV/AIDS $(n=10)$, and reproductive health $(\mathrm{n}=11)$. Tuberculosis, mental health, and asthma treatment all had 5 or less studies dedicated to the outcome and IPs.

Across the studies, drug sellers $(n=45)$ were the most common type of IP, followed by papers that discussed multiple kinds of IPs $(\mathrm{n}=30)$, TBAs $(\mathrm{n}=18)$, village doctors $(\mathrm{n}=19)$ and finally those that studied an informal brand of CHW $(n=5)$. Depending on the regulatory and enforcement environment, many drug sellers operate beyond their legal capacity by selling prescription-only medications as well as offering diagnostic and therapeutic medical advice [88]. Regulatory infringements are commonplace among drug sellers [15]. Some drug sellers have itinerant or mobile vending operations, but the extent of this practice is unclear and likely due in part to research challenges to completely capture the process [15].

The activity of village doctors and traditional medical practitioners is less consistent. Some village doctors have practices nearly indistinguishable from those of licensed allopathic physicians [116]. In some contexts, traditional practitioners primarily utilize non-allopathic modalities such as massage and herbal medicines [96], while in other situations they might supplant allopathic care completely [117]. An urban-rural division is apparent in some studies, which demonstrate that more rural populations are more likely to use village doctors and traditional practitioners than their urban counterparts $[25,38,68]$.

Traditional birth attendants (TBAs) play a role in pre- and postnatal care that ranges from acting as the sole caregiver to supporting trained birth attendants [112]. The term TBA encompasses providers of varying skill and training. In some cases a TBA is simply a family member while in other cases she practices regularly and relies on the work for an income, representing a spectrum of practice so broad that some researchers contend the term "TBA" is inappropriate to describe such heterogeneous pool [77]. The effectiveness of training programs for TBAs is the subject of an ongoing debate [113].

IPs generally practice poor preventive medicine, particularly IPs whose practice primarily consists of dispensing products or services in discrete units (e.g., drug sellers) $[59,69,118]$. Even those IPs who offer a more continuous and preventive brand of medicine (e.g., village doctors) might have a limited practice, centered around emergent situations, due to a general inability to pay for long-term health care in their community $[119,120]$.

\section{Size and Utilization Patterns in the Informal Health Care Sector}

Studies that discuss the size of the IP sector attempt to understand what proportion of all providers in a given geographical region are informal. Utilization patterns examined careseeking behavior and quantify patients' preferences for IPs. Relatively few studies $(n=24)$ document the utilization of IPs for health care services, and even fewer $(n=5)$ describe the size of the IP sector in relation to the health care provider pool overall. This review looked at studies in both categories, and is presented in Table 2.

Five studies reported the portion of all providers in a nation or region that are informal, ranging from $51 \%$ to $96 \%$. The methodologies in these studies have inherent limitations including cross-sectional designs, small sample size, and unclear classifications of informal providers, which may explain the wide variation. In Bangladesh, researchers estimated that $87 \%$ of providers were informal [59], while in the rural region of Chakaria, 96\% of all providers were informal [64]. In India the informal sector was found to be between $51-55 \%$ of all providers $[68,80]$. In Uganda, $77 \%$ of providers were found to be informal [32].

Utilization was defined in most cases as the first choice for care, but in other studies utilization was defined as the exclusive choice or as having played any role in care. Utilization estimates from 24 studies in the literature of IP for healthcare services ranged from $9 \%$ to $90 \%$, depending on the country, the disease in question, and methods of measurement (see Table 2). For example, in Bangladesh, utilization of IPs was consistently high across studies ranging from $60 \%-77 \%$. Using a large nationally representative survey of Bangladesh, one study found that $65 \%$ of individuals went to an informal healthcare provider for care [75]. Studies of Kenya, on the other hand, ranged from $9 \%-33 \%$ for IP consultation for fevers $[6,20]$.

Within countries, some studies have consistent findings (i.e. as in Nigeria, where four studies found results within ten percentage points of one another) $[9,121]$ while others arrive at vastly different results: three studies from Uganda featured a spread of over 50 percentage points $[9,26,32,37,121,122]$. In some cases, utilization data seemed to reflect the varying popularity of different types of IP, with studies including drug sellers consistently demonstrating higher utilization numbers (see Table 2).

\section{Quality of Informal Providers}

Out of the 122 articles, we identified 29 that reported on a clinical quality outcome (see Table 3 ). Most studies on quality are abstracted from interventions (16/29 articles), and 13 articles were from cross-sectional studies. Seventeen of the articles had a comparison group in order to assess quality of providers, five of which included a formal sector control. In the case of intervention studies, almost all reported on baseline characteristics and postintervention results (pre-post design), or compared experimental vs. control groups.

While measuring quality of care is difficult, there are a variety of methods used across the studies. Eight studies used mystery clients, or simulated standardized patients, to assess quality [86,88]. The standardized patient methodology is considered to be the "gold standard" for measuring clinical quality for a number of reasons: First, other methods are subject to observational biases (i.e. direct clinical observations), recall bias (patient exit interviews), and informational bias (i.e. chart abstraction). Standardized, simulated patients are able to give a more complete and valid comparison 
across a wide range of providers. We identified studies that reported technical or perceived dimensions of quality (as opposed to reporting on provider-specific characteristics, such as reporting only on provider knowledge). Technical quality included adequacy of health provision determined by existing guidelines (i.e. national guidelines), counseling, referral rates, and health practice. Studies that reported on perceived quality, as reported by clients, were also included in the literature review. Quality predictors identified in the studies include: 1) provider knowledge and skills; 2) adherence to clinical guidelines; 3) patient satisfaction.

Provider knowledge was variable across studies. Compared to the formal sector, training among IPs are limited across multiple health outcomes, and they lack necessary training and capacity to provide basic curative services [59,76,86]; however, two studies also found no difference in clinical quality when comparing formal and informal providers [26,101]. Compared to community health workers and allopathic paraprofessionals, IPs scored lower on adequate drug provision based on provider surveys [59]. In addition, there were also gaps in knowledge and practice, perhaps due to lack of resources, access, and drug availability [19].

Studies also found poor adherence to clinical national guidelines [26,51,55,90]. For example, in Vietnam, Chuc (2001) [90] found that only $36 \%$ of pharmacists dispensed antibiotics according to national guidelines; $41 \%$ used traditional medicines. Jacobs (2004) [26] found that only $7 \%$ of clients were properly managed according to national guidelines, including both clients who went to private clinics as well as drug shops.

Interventions assessed the impact of training on the clinical quality of providers. Fourteen out of sixteen training interventions resulted in positive quality outcomes (either pre/post test or increased quality compared to comparison groups) (see Table 3). Two studies reported mixed results for interventions [99]. Chalker [88] found that enforcement of regulations, increased education, and peer review effectively changed practices for management of dispensing medication in Hanoi; however, in Bangkok, the intervention only improved reduction in illegal dispensing of steroids, while other practices remained the same pre and postintervention. The authors attributed this to the voluntary nature of peer review in Bangkok, as opposed to mandatory activities in Vietnam, suggesting the peer review process as an important component of sustained change [88]. Based on these studies, training improved quality, but longer follow-up periods are necessary in order to address issues of sustainability. One study on a youth-friendly training intervention that was implemented in 30 pharmacies reported on perceived patient satisfaction and relationship with providers [103]. Mystery clients (blinded to who received and did not receive intervention) visited trained and untrained pharmacists and rated them on perceived trust, friendliness, practices, and counseling. Pharmacists who received youth-friendly training were rated higher across all four domains of patient satisfaction.

\section{Reasons People Use Informal Providers: Convenience, Affordability, and Culture}

There are three principal reasons for using IPs: convenience, affordability, and social and cultural effects. Compared to either the public or formal private sectors, IPs have flexible working hours and are likely to be open at all hours, more likely to have medicines in stock, generally geographically closer, and offer more rapid service. A study in West Bengal noted that the two most commonly cited reasons for visiting an IP were the proximity of location and the longer and more flexible business hours $74 \%$ and $65 \%$ of respondents, respectively) [123]. In a review of drug sellers, Goodman et al. (2007) [16] reported that IPs were closer, faster, and better stocked than formal caregivers $[15,16]$. IPs are typically considered a one-stop shop, and men seeking treatment for STDs in Thailand cited a preference for IPs due to their convenience [124].

IPs are more affordable than private sector providers and may even be more affordable than publicly administered free clinics when transport and informal payments are considered [6]. A study in Bangladesh found that $61 \%$ of respondents cited affordability as an important reason for visiting an IP [123]. One way IPs lower prices is to repackage medications into smaller, more affordable units [15]. While formal providers may offer subsidized or free goods and services, researchers report that irregularity in such benefits reduces their overall attraction [30]. While formal providers charge for diagnostics, procedures, and fees, IPs primarily accrue payment through up-front consultation fees and the dispensing of medications [63]. This matters to patients: one study found that $73 \%$ of women who visited drug sellers were not worried about the quality of the drug because cost was more important [98].

IPs may also accept in-kind payment when patients have no cash. Many studies cite transport costs as an indirect but important element that increases the cost of care by formal providers, who are often located farther from the patients' homes [71]. Indirect transport costs may exceed direct costs of care associated with formal providers $[6,64,125]$.

A study in Bangladesh found that the median cost of treatment of visiting a formal physician was five and fifteen times higher compared to visiting a village doctor or traditional healer, respectively [64]. The study did not control for varying levels of sickness; therefore, it is possible that patients self-select into formal providers when they are sicker, thereby incurring higher treatment costs on average in the formal sector. However, other evidence from Bangladesh suggests that even when illnesses are serious enough to require multiple visits, IPs remain substantially cheaper than their formal counterparts [63].

In addition, IPs often possess social and cultural advantages over formal private and public providers due to their status in the community. For example, they are subject to a greater degree of perceived accountability due to their geographic and social proximity to patients; they can better evaluate the trustworthiness of individuals and may offer creative financing for goods or services as a result; and their experiences, qualifications, and track record are all noted within a community, resulting in trust and respect [126]. The scope of practice of IPs is uniquely tied to community-level factors, more so than for formal providers [2]. IPs run smaller, more localized operations [49]. Much of their practice is contingent on the maintenance of good relationships with their communities. This aspect of practice for IPs is tied to their more forgiving and creative payment policies, whereby patients might be put on a sliding scale or deferred payment plan in accordance with their ability to pay. Such practices tend to buttress their role in the community, and thereby strengthen their business position [56].

Researchers have noted that IPs could be perceived as a more suitable option by family decision-makers, particularly for women's reproductive health care [30]. IPs that perform home visits and are well known within the community offer a degree of security that is difficult for more centralized formal providers to achieve when dealing with sensitive health issues [126]. While public clinics may see significant staff turnover and staff may be relatively young and inexperienced, IPs offer a more trustworthy and stable environment, where staff are part of the community and reputations are well established [30]. 


\section{Recommendations for Informal Providers}

We evaluated the recommendations in each study regarding IPs, and created a classification system for recommendations that was informed by previous work on the topic [16]. The categories include: 1) education interventions including capacity building exercises and training programs; 2) oversight interventions including regulation, enforcement, and registration; 3) process interventions including collaboration and engagement; 4) recognizing the social and cultural value that IPs offer foremost; 5) conducting further research on IPs (no other recommendations provided); and 6) reducing the need for IPs by improving access to formal providers.

Using this categorization, we abstracted the most important two recommendations per reference and recorded these in a database. Next, we tallied the overall frequency of recommendations in an attempt to characterize the literature's view on IPs. Of 195 papers that had recommendations, the most common (66 studies) were educational interventions, including capacity-building training programs for IPs, patient education programs, and continuing education requirements. Sixty-one publications called for oversight interventions including increased government oversight and regulation, as well as professional associations and other means for quality assurance. Process interventions were the third most-recommended intervention type (38 studies). These include building dialogue and understanding, and fostering working relationships between formal and informal providers. Eleven papers suggested that governments and researchers should recognize the social or cultural value of IPs, and ten papers only called for more research on IPs. Improving access to formal providers was the least cited recommendation (nine studies).

\section{Discussion}

In the developing world, informal providers represent a significant portion of the healthcare system. This review is the first comprehensive view of studies focusing on the size, scope, and quality of IPs, and is timely given this growing sector of the health system. This review revealed that studies on informal providers are limited in their methodology, scope, and descriptive ability, and evidence regarding the size, utilization, and quality of the informal sector is scarce. While there is wide variation across studies and countries on how large the sector truly is, it is clear that informal providers make up a large proportion of the health care provided, particularly among poor populations, and they fill a significant role in the health market. IPs covered a broad range of health areas including maternal and child health, malaria, HIV/AIDS, and reproductive health. Informal providers are serving multiple functions in the delivery of healthcare and include drug sellers, traditional birth attendants, and village doctors.

There was a dearth of information on the size of the informal provider sector as well as utilization rates. This study found huge variations in the size of the informal provider sector (51\% to $96 \%$ ), and an even greater range in utilization patterns (9\% to $90 \%)$. These significant ranges may be explained by study variations and regional differences. Variations in sample size and sampling techniques make it difficult to compare across studies. While some studies were nationally representative, the majority of studies were small in sample and regionally specific. For example, a focusedstudy in a poor region of a country known to have a high proportion of informal providers would provide much different results compared to a national survey of providers given that we know that the poor are more reliant on this sector. Types of informal providers in the study also differed across region; some studies were more inclusive and surveyed a number of types of the formal sector (i.e. village doctors, medical vendors, compounders), while others focused specifically on one type of provider. This makes it difficult to truly assess the proportion of informal providers in a given health market. Moreover, in order to fully summarize the size of the informal provider sector, a deeper understanding of local health markets and the role of the formal sector is critical. This remains a significant challenge, and is an opportunity for future health systems research.

In addition, this study highlights why people choose to go to informal providers. Poor populations are most likely to seek care from this sector [1], and convenience, affordability, and cultural factors were the most commonly cited reasons. Informal providers fill a significant gap in healthcare delivery particularly for individuals without the means to travel to public facilities or afford health insurance. Travel costs are an indirect, but important element, in increasing the cost of care from the formal sector. In countries such as Bangladesh, public facilities are not well stocked with appropriate drugs and are typically overwhelmed with long lines and a scarcity of physicians and nurses. In particular, while affordability and convenience may not seem surprising in the decision to visit an informal provider, as documented by the literature, the role of culture and values plays a particularly significant role. Cultural values dictate patient preferences, and the status and reputation of providers in communities, trust in informal providers (and distrust of the formal sector), and increased anonymity given certain visits (i.e. family planning) are all factors that influence where people go for medical care. Governments, donors, and NGOs should take these factors in to account when developing interventions that target the poor.

Quality was variable across contexts, and studies demonstrated that there was generally low provider knowledge, inadequate drug provision, and gaps in knowledge and practice. One study found that even with adequate training, clinical quality trails behind knowledge due to lack of resources, access, and drug availability [19]; in other words, provider knowledge is insufficient as a measure of clinical quality. Moreover, drug vendors are the most commonly cited informal provider, despite findings that the majority lacked training to provide basic primary care services [59]. Engaging these providers in to the mainstream health system to provide appropriate drug dosages and referrals may be a feasible way to broadly reach poorer populations.

This review also highlighted recommendations to better support informal providers. Educational interventions, including capacity building exercises and training programs, were the most commonly cited strategy for engaging IPs. Other recommendations included increased government oversight and regulation, process interventions, and finally, greater access to formal providers. Given that affordability and convenience were reasons given for tapping in to IPs, the formal sector may incorporate strategies for addressing these gaps to better reach the poor. A systematic review of the literature identified the most effective interventions as ones that combined educational training with improving market conditions, such as provider incentives and accountability [127]. Interventions that do not rely solely on individual-level behavior changes, but also combine market-based approaches and rigorous evaluations, may prove to be most successful in improving quality. In addition, collaborating with a local advisory board as well as partners who were committed to long-term change were important lessons learned from implementing a successful intervention [103].

There are a number of limitations in this review given the paucity of research on informal providers. This review aimed to be inclusive of studies on informal providers, and therefore, a range of study designs and samples are used. Comparability across studies was difficult. First, cross-sectional studies assessing interventions is 
limited in its' ability to establish causality. Studies lacking baseline data or comparison groups, including pre/post data or IPs vs. nonIPs, are unable to truly assess the effects of interventions. Second, because some studies in the review include limited sample size, external validity and generalizability may be an issue. Study results and implications should not be extrapolated outside the study sample. In addition, there are a number of potential limitations in the review. For example, because of publication bias, the review may overestimate specific interventions- statistically significant interventions may be more likely to be accepted for publication. However, this review explores both peer-reviewed and grey literature, and therefore may have been more likely to capture non-significant studies compared to only searching published literature. In addition, because of the wide variation in study designs and types of providers included in the literature review, the heterogeneity of the sector is not explored in this review. This warrants further investigation into subsets of informal providers and analysis of the types of quality issues specific to providers.

Limitations in the literature suggest that further research is needed in order to fully understand this growing sector. In particular, because informal providers typically work outside the purviews of a regulatory framework, there is little information on the quality of services delivered by IPs. What information there is suggests that quality of care is poor, and this may pose risk to the most vulnerable populations. Specific research studies should focus on better understanding local health markets as well as documenting key characteristics of the informal provider sector. This research is needed in a number of areas:

First, the definition of informal providers needs further assessment. Because the formal sector's increasing recognition that IPs play a significant role, engagement with this sector has started to change and therefore definitions need to be adapted accordingly. While the definition used in the review may be

\section{References}

1. Bloom G, Standing H, Lucas H, Bhuiya A, Oladepo O, et al. (2011) Making health markets work better for poor people: the case of informal providers. Health Policy Plan 26 Suppl 1: i45-52.

2. Cross J, MacGregor HN (2010) Knowledge, legitimacy and economic practice in informal markets for medicine: a critical review of research. Soc Sci Med 71: 1593-1600.

3. Abuya T, Fegan G, Rowa Y, Karisa B, Ochola S, et al. (2009) Impact of ministry of health interventions on private medicine retailer knowledge and practices on anti-malarial treatment in Kenya. Am J Trop Med Hyg 80: 905913.

4. Abuya TO, Mutemi W, Karisa B, Ochola SA, Fegan G, et al. (2007) Use of over-the-counter malaria medicines in children and adults in three districts in Kenva: implications for private medicine retailer interventions. Malar J 6: 57.

5. Adu-Sarkodie Y, Steiner MJ, Attafuah J, Tweedy K (2000) Syndromic management of urethral discharge in Ghanaian pharmacies. Sexually Transmitted Infections 76: 439-442.

6. Amin AA, Marsh V, Noor AM, Ochola SA, Snow RW (2003) The use of formal and informal curative services in the management of paediatric fevers in four districts in Kenya. Trop Med Int Health 8: 1143-1152.

7. Amzat J, Abdullahi AA (2008) Roles of Traditional Healers in the Fight Against HIV/AIDS. Ethno-Med 2: 153-159.

8. Battersby A, Goodman C, Abondo C, Mandike R (2003) Improving the Supply, Distribution and Use of Antimalarial Drugs by the Private Sector in Tanzania. Malaria Consortium, London.

9. Brieger WR, Salako LA, Umeh RE, Agomo PU, Afolabi BM, et al. (2001) Promoting prepackaged drugs for prompt and appropriate treatment of febrile illnesses in rural Nigerian communities. International Quarterly of Community Health Education 21: 19-40.

10. Brieger WR, Osamor PE, Salami KK, Oladepo O, Otusanya SA (2004) Interactions between patent medicine vendors and customers in urban and rural Nigeria. Health Policy and Plan 19: 177-182.

11. Colvin M, Gumede L, Grimwade K, Maher D, Wilkinson D (2003) Contribution of traditional healers to a rural tuberculosis control programme in Hlabisa, South Africa. The International Journal of Tuberculosis and Lung Disease 7: S86-S91.

12. Dzator J, Asafu-Adjaye J (2004) A study of malaria care provider choice in Ghana. Health Policy 69: 389-401. debatable, it was needed to delineate which studies and types of providers should be included under the term 'informal provider'. Further public discussion on this is needed. Second, future studies should focus on specific types of informal providers, and specific services, in order to help with strategies of engagement. The informal provider sector is a heterogeneous group, and targeted interventions and policies can reflect this. Third, understanding user choices and patient knowledge is important. Studies would benefit from understanding networks of providers and patients and what are the decision-making factors that influence choice in care. Fourth, future studies need to focus on quality of providers, using robust study designs and measures. This literature review suggests that knowledge, for example, is not an adequate measure of quality and needs to be combined with measures of technical competence and perceived quality of care. Lastly, a deeper understanding of local health markets, the relationship with the formal sector, and a mapping of providers in a community will help researchers, donors, and policy-makers target care appropriately. While many questions remain, it is clear that greater attention is needed to engage informal providers in order to assure that patients in developing countries, particularly poor patients, have access to appropriate and safe medical care.

\section{Acknowledgments}

The authors would like to acknowledge Brittany Zelman and Naomi Beyeler for their assistance in organizing references.

\section{Author Contributions}

Conceived and designed the experiments: MS MI HL DM. Performed the experiments: MS MI HL DM. Analyzed the data: MS MI HL DM. Contributed reagents/materials/analysis tools: MS MI HL DM. Wrote the paper: MS MI HL DM.

13. Ene-Obong HN, Iroegbu GU, Uwaegbute AC (2000) Perceived causes and management of diarrhoea in young children by market women in Enugu State, Nigeria. Journal of Health Population and Nutrition 18: 97-102.

14. Gloyd S, Floriano F, Seunda M, Chadreque MA, Nyangezi JM, et al. (2001) Impact of traditional birth attendant training in Mozambique: a controlled study. J Midwifery Womens Health 46: 210-216.

15. Goodman C, Kachur SP, Abdulla S, Bloland P, Mills A (2007) Drug shop regulation and malaria treatment in Tanzania-why do shops break the rules, and does it matter? Health Policy Plan 22: 393-403.

16. Goodman C, Brieger W, Unwin A, Mills A, Meek S, et al. (2007) Medicine sellers and malaria treatment in sub-Saharan Africa: what do they do and how can their practice be improved? Am J Trop Med Hyg 77: 203-218.

17. Goodman CA, Mutemi WM, Baya EK, Willetts A, Marsh V (2006) The costeffectiveness of improving malaria home management: shopkeeper training in rural Kenya. Health Policy Plan 21: 275-288.

18. Goodman C, Kachur SP, Abdulla S, Bloland P, Mills A (2007) Drug shop regulation and malaria treatment in Tanzania: why do shops break the rules, and does it matter? Health Policy and Plan 22: 393-403.

19. Greer G, Akinpelumi A, Madueke L, Plowman B, Fapohunda B, et al. (2004) Improving Management of Childhood Malaria in Nigeria and Uganda by Improving Practices of Patent Medicine Vendors. Arlington, Va.: BASICS II for the United States Agency for International Development.

20. Hamel MJ, Odhacha A, Roberts JM, Deming MS (2001) Malaria control in Bungoma District, Kenya: a survey of home treatment of children with fever, bednet use and attendance at antenatal clinics. Bull World Health Organ 79: 1014-1023.

21. Hill AG, MacLeod WB, Joof D, Gomez P, Walraven G (2000) Decline of mortality in children in rural Gambia: the influence of village-level Primary Health Care. Trop Med Int Health 5: 107-118.

22. Homan R, Searle C, Esu-Williams E, Aguirre M, Mafata S, et al. (2005) Exploring the Role of Family Caregivers and Home-Based Care Programs in Meeting the Needs of People Living with HIV/AIDS. Horizons Research Update.

23. Homsy J, King R, Tenywa J, Kyeyune P, Opio A, et al. (2004) Defining minimum standards of practice for incorporating African traditional medicine into HIV/AIDS prevention, care, and support: a regional initiative in eastern and southern Africa. J Altern Complement Med 10: 905-910. 
24. Homsy J, King R, Balaba D, Kabatesi D (2004) Traditional health practitioners are key to scaling up comprehensive care for HIV/AIDS in sub-Saharan Africa. Aids 18: 1723-1725.

25. Izugbara C, Afangideh A (2005) Urban women's use of rural-based health care services: The case of Igbo women in Aba city, Nigeria. Journal of Urban Health 82: 111-121.

26. Jacobs B, Whitworth J, Kambugu F, Pool R (2004) Sexually transmitted disease management in Uganda's private-for-profit formal and informal sector and compliance with treatment. Sex Transm Dis 31: 650-654.

27. Kaboru B, Falkenberg T, Ndubani P, Hojer B, Vongo R, et al. (2006) Can biomedical and traditional health care providers work together? Zambian practitioners' experiences and attitudes towards collaboration in relation to STIs and HIV/AIDS care: a cross-sectional study. Human Resources for Health 4: 16

28. Kayombo EJ, Mbwambo ZH, Massila M (2005) Role of traditional healers in psychosocial support in caring for the orphans: a case of Dar-es Salaam City, Tanzania. J Ethnobiol Ethnomed 1: 3.

29. Kayombo EJ, Uiso FC, Mbwambo ZH, Mahunnah RL, Moshi MJ, et al. (2007) Experience of initiating collaboration of traditional healers in managing HIV and AIDS in Tanzania. J Ethnobiol Ethnomed 3: 6.

30. Kiapi-Iwa L, Hart GJ (2004) The sexual and reproductive health of young people in Adjumani district, Uganda: qualitative study of the role of formal, informal and traditional health providers. AIDS Care 16: 339-347.

31. King R (2000) Collaboration with Traditional Healers in HIV/AIDS Prevention and Care in Sub-Saharan Africa: A Literature Review. UN AIDS.

32. Konde-Lule J, Gitta S, Lindfors A, Okuonzi S, Onama V, et al. (2010) Private and public health care in rural areas of Uganda. BMC International Health and Human Rights 10: 29.

33. Marsh VM, Mutemi WM, Willetts A, Bayah K, Were S, et al. (2004) Improving malaria home treatment by training drug retailers in rural Kenya. Trop Med Int Health 9: 451-460.

34. Nshakira N, Kristensen M, Ssali F, Whyte SR (2002) Appropriate treatment of malaria? Use of antimalarial drugs for children's fevers in district medical units, drug shops and homes in eastern Uganda. Trop Med Int Health 7: 309-316.

35. Nsimba SE (2007) Assessing the impact of educational intervention for improving management of malaria and other childhood illnesses in Kibaha District-Tanzania. East Afr J Public Health 4: 5-11.

36. Okeke T, Uzochukwu B, Okafor H (2006) An in-depth study of patent medicine sellers' perspectives on malaria in a rural Nigerian community. Malaria J 5: 97

37. Oladepo O, Salami KK, Adeoye BW, Oashiname F, Ofi B, et al. (2007) Malaria treatment and policy in three regions in Nigeria: The role of patent medical vendors. Futurs Health Systems.

38. Onwujekwe O, Hanson K, Uzochukwu B, Ichoku H, Ike E, et al. (2010) Are malaria treatment expenditures catastrophic to different socio-economic and geographic groups and how do they cope with payment? A study in southeast Nigeria. Trop Med Int Health 15: 18-25.

39. Onwujekwe O, Dike N, Uzochukwu B, Ezeoke O (2010) Informal payments for healthcare: differences in expenditures from consumers and providers perspectives for treatment of malaria in Nigeria. Health Policy 96: 72-79.

40. Onwujekwe O, Hanson K, Uzochukwu B, Ezeoke O, Eze S, et al. (2010) Geographic inequities in provision and utilization of malaria treatment services in southeast Nigeria: diagnosis, providers and drugs. Health Policy 94: 144149.

41. Peltzer K, Mngqundaniso N, Petros G (2006) A controlled study of an HIV/ AIDS/STI/TB intervention with traditional healers in KwaZulu-Natal, South Africa. AIDS Behav 10: 683-690.

42. Peltzer K, Preez NF, Ramlagan S, Fomundam H (2008) Use of traditional complementary and alternative medicine for HIV patients in KwaZulu-Natal, South Africa. BMC Public Health 8: 255.

43. Peu MD, Troskie R, Hattingh SP (2001) The attitude of community health nurses towards integration of traditional healers in primary health care in north-west province. Curationis 24: 49-55.

44. Ram PK, Kelsey E, Rasoatiana, Miarintsoa RR, Rakotomalala O, et al. (2007) Bringing Safe Water to Remote Populations: An Evaluation of a Portable Point-of-Use Intervention in Rural Madagascar. American Journal of Public Health 97: 398-400.

45. Rutta E, Senauer K, Johnson K, Adeya G, Mbwasi R, et al. (2009) Creating a new class of pharmaceutical services provider for underserved areas: the Tanzania accredited drug dispensing outlet experience. Prog Community Health Partnersh 3: 145-153.

46. Smith F (2009) Private local pharmacies in low- and middle-income countries: a review of interventions to enhance their role in public health. Trop Med Int Health 14: 362-372.

47. Smith F (2004) Community pharmacy in Ghana: enhancing the contribution to primary health care. Health Policy and Plan 19: 234-241.

48. Tavrow P, Shabahang J, Makama S (2003) Vendor-to-vendor education to improve malaria treatment by private drug outlets in Bungoma District, Kenya. Malar J 2: 7.

49. Tawfik Y, Northrup R, Prysor-Jones SG (2002) Utilizing the potential of formal and informal private practitioners in child survival: situation analysis and summary of promising interventions. SARA Project, Academy for Educational Development.
50. Tawfik Y, Nsungwa-Sabitii J, Greer G, Owor J, Kesande R, et al. (2006) Negotiating improved case management of childhood illness with formal and informal private practitioners in Uganda. Trop Med Int Health 11: 967-973.

51. Taylor RB, Shakoor O, Behrens RH, Everard M, Low AS, et al. (2001) Pharmacopoeial quality of drugs supplied by Nigerian pharmacies. The Lancet 357: 1933-1936.

52. Tipke M, Louis VR, Ye M, De Allegri M, Beiersmann C, et al. (2009) Access to malaria treatment in young children of rural Burkina Faso. Malar J 8: 266.

53. Twabeze D (2001) A literature review of care-seeking practices for major childhood illnesses in Uganda. Washington, D.C.: Basic Support for Institutionalizing Child Survival Project (BASICS II). Arlington, Virginia: United States Agency for International Development.

54. van den Boogaard J, Arntzen B, Chilwana J, Liyungu M, Mantingh A, et al. (2008) Skilled or traditional birth attendant? Choices of communities in Lukulu District, rural Zambia. World Health Popul 10: 34-43.

55. Viberg N, Mujinja P, Kalala W, Kumaranayake L, Vyas S, et al. (2009) STI management in Tanzanian private drugstores: practices and roles of drug sellers. Sexually Transmitted Infections 85: 300-308.

56. Walker D, Muyinda H, Foster S, Kengeya-Kayondo J, Whitworth J (2001) The quality of care by private practitioners for sexually transmitted diseases in Uganda. Health Policy and Plan16: 35-40.

57. Ahmed SM, Adams AM, Chowdhury M, Bhuiya A (2003) Changing healthseeking behaviour in Matlab, Bangladesh: do development interventions matter? Health Policy and Plan 18: 306-315.

58. Ahmed SM, Hossain MA (2007) Knowledge and practice of unqualified and semi-qualified allopathic providers in rural Bangladesh: Implications for the HRH problem. Health Policy 84: 332-343.

59. Ahmed SM, Hossain MA, Chowdhury MR (2009) Informal sector providers in Bangladesh: how equipped are they to provide rational health care? Health Policy and Plan 24: 467-478.

60. Attanayake N, Siyambalagoda L (2009) An inquiry into the regulation of pharmaceuticals and medical practice in Sri Lanka. Working Papers.

61. Bang AT, Bang RA, Baitule SB, Reddy HM, Deshmukh MD (2005) Management of Birth Asphyxia in Home Deliveries in Rural Gadchiroli: The Effect of Two Types of Birth Attendants and of Resuscitating with Mouthto-Mouth, Tube-Mask or Bag-Mask. J Perinatol 25: S82-S91.

62. Bang AT, Baitule SB, Reddy HM, Deshmukh MD, Bang RA (2005) Low Birth Weight and Preterm Neonates: Can they be Managed at Home by Mother and a Trained Village Health Worker? J Perinatol 25: S72-S81.

63. Baqui AH, El-Arifeen S, Darmstadt GL, Ahmed S, Williams EK, et al. (2008) Effect of community-based newborn-care intervention package implemented through two service-delivery strategies in Sylhet district, Bangladesh: a clusterrandomised controlled trial. The Lancet 371: 1936-1944.

64. Bhuiya A (2009) Health for the rural masses: Insights from Chakaria. Dhaka, Bangladesh: ICDDR,B.

65. Collumbien M, Douthwaite M (2003) Pills, injections and audiotapes: reaching couples in Pakistan. J Biosoc Sci 35: 41-58.

66. De Costa A, Diwan V (2007) 'Where is the public health sector?': Public and private sector healthcare provision in Madhya Pradesh, India. Health Policy 84: 269-276.

67. De Costa A, Johansson E, Diwan VK (2008) Barriers of Mistrust: Public and Private Health Sectors' Perceptions of Each Other in Madhya Pradesh, India. Qualitative Health Research 18: 756-766.

68. De Costa A, Al-Muniri A, Diwan VK, Eriksson B (2009) Where are healthcare providers? Exploring relationships between context and human resources for health Madhya Pradesh province, India. Health Policy 93: 41-47.

69. Ecks S, Basu S (2009) The unlicensed lives of antidepressants in India: generic drugs, unqualified practitioners, and floating prescriptions. Transcult Psychiatry 46: 86-106.

70. Hosain GM, Ganguly KC, Chatterjee N, Atkinson D (2005) Use of unqualified practitioners by disabled people in rural Bangladesh. Mymensingh Med J 14: $160-164$.

71. ICDDR B (2009) Costs of utilization healthcare services in Chakaria, a rural area in Bangladesh. Dhaka, Bangladesh: Policy.

72. Jokhio AH, Winter HR, Cheng KK (2005) An Intervention Involving Traditional Birth Attendants and Perinatal and Maternal Mortality in Pakistan. New England Journal of Medicine 352: 2091-2099.

73. Kanjilal B, Mondal S, Samanta T, Mondal A, Singh S (2007) A Parallel Health Care Market: Rural Medical Practitioners in West Bengal, India. Future Health Systems (FHS) Research Brief 2: 4.

74. Khan M, Saha K, Ahmed S (2011) Adopting Integrated Management of Childhood Illness Module at Local Level in Bangladesh: Implications for Recurrent Costs. Journal of Health Population and Nutrition 20: 42-50.

75. Levin A, Rahman MA, Quayyum Z, Routh S, Barkat e K (2001) The demand for child curative care in two rural thanas of Bangladesh: effect of income and women's employment. The International Journal of Health Planning and Management 16: 179-194.

76. Mignone J, Washington RG, Ramesh BM, Blanchard JF, Moses S (2007) Formal and informal sector health providers in southern India: role in the prevention and care of sexually transmitted infections, including HIV/AIDS. AIDS Care 19: 152-158.

77. Parkhurst JO, Rahman SA (2007) Non-professional health practitioners and referrals to facilities: lessons from maternal care in Bangladesh. Health Policy and Plan 22: 149-155. 
78. Poudyal AK, Jimba M, Murakami I, Silwal RC, Wakai S, et al. (2003) A traditional healers' training model in rural Nepal: strengthening their roles in community health. Trop Med Int Health 8: 956-960.

79. Rahman A (2007) Challenges and opportunities in developing a psychological intervention for perinatal depression in rural Pakistan - a multi-method study. Archives of Women's Mental Health 10: 211-219.

80. Rao PH (2005) Profile and Practice of Private Medical Practitioner in Rural India. Healht and Population Perspectives and Issues 28: 40-49.

81. Rowen T, Prata N, Passano P (2009) Evaluation of a traditional birth attendant training programme in Bangladesh. Midwifery.

82. Salim H, Uplekar M, Daru P, Aung M, Declercq E, et al. (2006) Turning Liabilities into Resources: Informal Village Doctors and Tuberculosis Control in Bangladesh. Bull World Health Organ 84: 479-484.

83. Van Sickle D (2006) Management of asthma at private pharmacies in India. The International Journal of Tuberculosis and Lung Disease 10: 1386-1392.

84. Ali A, Howden-Chapman P (2007) Maternity services and the role of the traditional birth attendant, bidan kampung, in rural Malaysia. J Public Health Manag Pract 13: 278-286.

85. Bryant J, Prohmmo A (2001) Use of Drug Sellers by Old People in Northeast Thailand. Asia-Pacific Journal of Public Health 13: 91-95.

86. Chalker J, Chuc NTK, Falkenberg T, Do NT, Tomson G (2000) STD management by private pharmacies in Hanoi: practice and knowledge of drug sellers. Sexually Transmitted Infections 76: 299-302.

87. Chalker J, Chuc NTK, Falkenberg T, Tomson G (2002) Private pharmacies in Hanoi, Vietnam: a randomized trial of a 2-year multi-component intervention on knowledge and stated practice regarding ARI, STD and antibiotic/steroid requests. Trop Med Int Health 7: 803-810.

88. Chalker J, Ratanawijitrasin S, Chuc NTK, Petzold M, Tomson G (2005) Effectiveness of a multi-component intervention on dispensing practices at private pharmacies in Vietnam and Thailand: a randomized controlled trial. Soc Sci Med 60: 131-141

89. Chandy H, Steinholt M, Husum H (2007) Delivery life support: A preliminary report on the chain of survival for complicated deliveries in rural Cambodia. Nursing \& Health Sciences 9: 263-269.

90. Chuc NT, Larsson M, Falkenberg T, Do NT, Binh NT, et al. (2001) Management of childhood acute respiratory infections at private pharmacies in Vietnam. The Annals of Pharmacotherapy 35: 1283-1288.

91. Lonnroth K, Lambregts K, Nhien DTT, Quy HT, Diwan VK (2000) Private Pharmacies and Tuberculosis Control: A Survey of Case Detection Skills and Reported Anti-Tuberclosis Drug Dispensing in Private Pharmacies in Ho Chi Minh City, Vietnam. The International Journal of Tuberculosis and Lung Disease 4: 1052-1059.

92. Lonnroth K, Karlsson M, Lan NTN, Buu TN, Dieu TTN (2003) Referring TB Suspects from Private Pharmacies to the National Tuberculosis Programme: Experiences from Two Districts in Ho Chi Mihn City, Vietnam. the International Journal of Tuberculosis and Lung Disease 7: 1147-1153.

93. Singhal N, McMillan D, Cristobal F, Arciaga R, Hocson W, et al. (2001) Problem-Based Teaching of Birth Attendants in the Philippines. Health Care for Women International 22: 569-583.

94. Stenson B, Syhakhang L, Lundborg CS, Eriksson B, Tomson G (2001) Private Pharmacy Practice and Regulation. International Journal of Technology Assessment in health Care 14: 579-589.

95. Sychareun V (2004) Meeting the contraceptive needs of unmarried young people: attitudes of formal and informal sector providers in Vientiane Municipality, Lao PDR. Reprod Health Matters 12: 155-165.

96. Sydara K, Gneunphonsavath S, Wahlstram R, Freudenthal S, Houamboun K, et al. (2005) Use of traditional medicine in Lao PDR. Complementary Therapies in Medicine 13: 199-205.

97. Syhakhang L, Lundborg CS, Lindgren B, Tomson G (2004) The quality of drugs in private pharmacies in Lao PDR: a repeat study in 1997 and 1999. Pharmacy World \& Science 26: 333-338.

98. Syhakhang L, Freudenthal S, Tomson G, Wahlstram R (2004) Knowledge and perceptions of drug quality among drug sellers and consumers in Lao PDR. Health Policy and Plan 19: 391-401.

99. Bailey PE, Szaszdi JA, Glover L (2002) Obstetric complications: does training traditional birth attendants make a difference? Rev Panam Salud Publica 11: $15-23$

100. Garcia P, Hughes J, Carcamo C, Holmes KK (2003) Training pharmacy workers in recognition, management, and prevention of STDs: districtrandomized controlled trial. Bull World Health Organ 81: 806-814

101. Goldman N, Glei DA (2003) Evaluation of midwifery care: results from a survey in rural Guatemala. Soc Sci Med 56: 685-700.

102. Walsh LV (2006) Beliefs and rituals in traditional birth attendant practice in Guatemala. J Transcult Nurs 17: 148-154.
103. Wolfe K (2005) Youth Friendly Pharmacies and Partnerships: The MCSCELSAM Experience. Bethesda, MD: Private Sector Partnerships -One project, Abt Associates, Inc.

104. Brugha R (2003) Antiretroviral treatment in developing countries: the peril of neglecting private providers. BMJ 326: 1382-1384.

105. Cross J, MacGregor H (2009) Who Are 'Informal Health Providers' and What Do They Do? Perspectives from Medical Anthropology. IDS Working Papers 2009: 01-23

106. Kruske S, Barclay L (2004) Effect of shifting policies on traditional birth attendant training. J Midwifery Womens Health 49: 306-311.

107. Lonnroth K, Uplekar M, Blanc L (2006) Hard gains through soft contracts: productive engagement of private providers in tuberculosis control. Bull World Health Organ 84: 876-883.

108. Mills A, Brugha R, Hanson K, McPake B (2002) What can be done about the private health sector in low-income countries? World Hosp Health Serv 38: 24-30.

109. Patouillard E, Goodman C, Hanson K, Mills A (2007) Can working with the private for-profit sector improve utilization of quality health services by the poor? A systematic review of the literature. International Journal for Equity in Health 6: 17.

110. Sibley L, Sipe TA (2004) What can a meta-analysis tell us about traditional birth attendant training and pregnancy outcomes? Midwifery 20: 51-60.

111. Sibley L, Sipe TA, Koblinsky M (2004) Does traditional birth attendant training improve referral of women with obstetric complications: a review of the evidence. Soc Sci Med 59: 1757-1768.

112. Sibley LM, Sipe TA, Koblinsky M (2004) Does traditional birth attendant training increase use of antenatal care? A review of the evidence. J Midwifery Womens Health 49: 298-305.

113. Sibley LM, Sipe TA, Brown CM, Diallo MM, McNatt K, et al. (2007) Traditional birth attendant training for improving health behaviours and pregnancy outcomes. Cochrane Database Syst Rev CD005460.

114. van Roosmalen J, Walraven G, Stekelenburg J, Massawe S (2005) Editorial: integrating continuous support of the traditional birth attendant into obstetric care by skilled midwives and doctors: a cost-effective strategy to reduce perinatal mortality and unnecessary obstetric interventions. Trop Med Int Health 10: 393-394.

115. Waters H, Hatt L, Peters D (2003) Working with the private sector for child health. Health Policy Plan 18: 127-137.

116. Hamid Salim MA, Uplekar M, Daru P, Aung M, Declercq E, et al. (2006) Turning liabilities into resources: informal village doctors and tuberculosis control in Bangladesh. Bull World Health Organ 84: 479-484.

117. Warren DM, Bova GS, Tregoning MA, Kliewer M (1982) Ghanaian National Policy toward Indigenous Healers - the Case of the Primary Health Training for Indigenous Healers (Prhetih) Program. Soc Sci Med 16: 1873-1881.

118. Smith JB, Coleman NA, Fortney JA, Johnson JD, Blumhagen DW, et al. (2000) The impact of traditional birth attendant training on delivery complications in Ghana. Health Policy Plan 15: 326-331.

119. Kumar R, Jaiswal V, Tripathi S, Kumar A, Idris MZ (2007) Inequity in health care delivery in India: the problem of rural medical practitioners. Health Care Anal 15: 223-233.

120. Gai R, Xu L, Wang X, Liu Z, Cheng J, et al. (2008) The role of village doctors on tuberculosis control and the DOTS strategy in Shandong Province, China. Biosci Trends 2: 181-186.

121. Enato EF, Okhamafe AO (2006) A survey of anti-malarial activity during pregnancy, and children's malaria care-seeking behaviour in two Nigerian rural communities. Scand J Infect Dis 38: 474-478.

122. Salako LA, Brieger WR, Afolabi BM, Umeh RE, Agomo PU, et al. (2001) Treatment of childhood fevers and other illnesses in three rural Nigerian communities. J Trop Pediatr 47: 230-238.

123. Barun Kanjilal SM, Samanta T., Mondal A, Singh S (2007) A Parallel Health Care Market: Rural Medical Practitioners in West Bengal, India. Institute of Health Management Research.

124. Benjarattanaporn P, Lindan CP, Mills S, Barclay J, Bennett A, et al. (1997) Men with sexually transmitted diseases in Bangkok: where do they go for treatment and why? AIDS 11 Suppl 1: S87-95.

125. Corno L (2008) Switching (or not) health seeking behavior: Evidence from rural Tanzania.

126. Ensor T, Witter S (2001) Health economics in low income countries: adapting to the reality of the unofficial economy. Health Policy 57: 1-13.

127. Shah NM, Brieger WR, Peters DH (2011) Can interventions improve health services from informal private providers in low and middle-income countries? a comprehensive review of the literature. Health Policy Plan 26: 275-287.

128. Chalker J, Chuc NTK, Falkenberg T, Tomson G (2002) Private pharmacies in Hanoi, Vietnam: a randomized trial of a 2-year multi-component intervention on knowledge and stated practice regarding ARI, STD and antibiotic/steroid requests. Trop Med Int Health 7: 803-810. 